\title{
Occupational Eye Injuries; Are They Preventable?
}

\author{
M. M. Dissanayake ${ }^{1}$, C. J. Silva ${ }^{2}$, P. H. Dissanayake ${ }^{3}$
}

\begin{abstract}
Introduction: Ocular trauma at workplace is a worldwide cause of visual morbidity. It could be prevented by compliance to proper protective eyewear and increasing awareness. Preventive strategies can be best developed by analyzing the patterns and epidemiology of injuries. This study was designed to evaluate patterns and epidemiology of occupational eye injuries with a view to developing preventive strategies.
\end{abstract}

Material and Methods: In this observational cross-sectional study, 152 ocular trauma patients presenting to Accident and Emergency service of National Eye Hospital, Colombo, Sri Lanka were enrolled. Data was obtained via an interviewer administered questionnaire and was analyzed by SPSS version 17.

Results: Majority of the participants were aged 18-28years (50.7\%). Males (96.1\%) had the highest incidence of ocular injuries. Most of the patients were the sole breadwinner $(84.2 \%)$ without life insurance $(85.5 \%)$ or savings $(62.5 \%)$ and are from low socioeconomic grounds $(61.8 \%)$. The cornea $(79.6 \%)$ was mostly affected; by superficial foreign bodies $(62.5 \%)$ and by closed globe injury (99.3\%).Greater number of ocular trauma was caused by physical means $(75.7 \%)$ by sharp objects $(67.8 \%)$. Majority of the participants $84.9 \%$ had not been using any eye protection at the time of injury. Protective eyewear was only provided at $44.7 \%$ of work places. Most of the patients attended the hospital 12-24 hours after (42.8\%) ocular trauma. Out of the patients who presented to the hospital $77 \%$ were not given any first aid.

Conclusion: Our results are comparable with those found in the literature. Promoting use of effective eye protection equipment and revision of the laws on occupational safety are some of the recommendations proposed to prevent occupational eye injuries.

\section{INTRODUCTION}

Ocular trauma at workplace is a worldwide cause of visual morbidity (1).
Consequences of occupational eye injuries are a cause of concern not only to the

\footnotetext{
1. Senior Lecturer, Consultant Ophthalmologist, Department of Anatomy, University of Colombo.

2. Research Assistant, Department of Anatomy, University of Colombo.

3. Senior Lecturer, Consultant Radiologist, Department of Anatomy, University of Sri Jayewardenepura
} 
DISSANAYAKE, M. M., SILVA, C. J., DISSANAYAKE, P. H., Occupational eye injuries; are they preventable? Sri Lanka Anatomy

individual and the family but collectively will have an impact on the productivity and the economy of a country (2). Furthermore the incidence of work related eye injuries show an increase over the last few years in many developed countries (3). It could be prevented by compliance to proper protective eyewear and increasing awareness (4,5). Preventive strategies can be best developed by analyzing the patterns and epidemiology of injuries. This study was designed to evaluate patterns and epidemiology of occupational eye injuries with a view to developing preventive strategies in Sri Lanka.

\section{METHODOLOGY}

The study was an observational cross sectional study carried out at the Accident and Emergency Service of the National eye hospital Colombo, during August 2012. This study was approved by the Ethics Review Committee, Faculty of Medicine, University of Colombo and followed the tenets of the Declaration of Helsinki.

Data of 152 patients presenting with a history of occupational eye injuries were obtained by Interviewer administered questionnaires and hospital records.

Data was analyzed using SPSS 17.0 software.

\section{RESULTS}

Ocular injuries were highest among males $(96.1 \%)$, the commonest age group affected was amongst 18-28years. Majority of the affected (61.2\%) were educated up to $\mathrm{O} / \mathrm{L}$ coming from an urban population $(72.4 \%)$.

In considering the occupation of the affected population, welders $(39.5 \%)$ were affected most and a considerable number affected were also handling chemicals (15.78\%). Non-skilled (74.3\%) work increased the risk for ocular injuries in comparison to skilled workers. Superficial foreign body was the commonest $(62.5 \%)$ diagnosis. The cornea $(79.6 \%)$ was the anatomical structure affected most with conjunctiva being the second commonest.

Greater number of ocular trauma was caused by physical means $(75.7 \%)$ mainly by sharp objects $(89.56 \%)$ and a lesser number caused by chemical injuries (23\%) mainly in the form of liquids $(82.85 \%)$ Eye protection was not used by $84.9 \%$ of workers at the time of injury even though $38.2 \%$ of them had a history of previous eye trauma.

It was interesting to note that $15.1 \%$ acquired ocular injury while wearing goggles as eye protection.

Out of the work places $44.7 \%$ did not provide protective eyewear and $89.5 \%$ did not provide facilities to wash eyes. 
Most of the patients (42.8\%) presented to the hospital 12-24 hours after the incident, and $77 \%$ of them did not receive any first aid at the time of injury.

Occupational eye injuries indicated a considerable impact on the family economy as most of the patients were the sole breadwinner $(84.2 \%)$ in low socioeconomic back ground with a monthly income of less than twenty five thousand rupees a month. (61.8\%). Majority of the patients were not possessing any form of life or medical insurance $(85.5 \%)$ or savings $(62.5 \%)$.

\section{CONCLUSIONS}

Our results are comparable with those found in the literature $(6,7)$. The population who suffer the most is young males who are the work force of the country. Welding is the commonest occupation leading to eye injuries despite repeated involvement. Non skilled work increases the risk. Cornea is the structure affected most, mainly via physical means. Frequent repeated ocular injuries are common at work place and it has a considerable impact on the family economy as well as the productivity of the work site. Majority does not use any eye protection during work and greater proportion of work places do not provide eye protection, or facilities to wash eyes in such ocular injuries as first aid.

\section{RECOMMENDATIONS}

At-risk population should receive increase attention in preventive strategies. Campaigns to increase awareness on occupational eye injuries among employees and employers are suggested with emphasis on the importance of early medical attention following ocular injury. Legislative implementations are recommended to prevent ocular injuries including, mandatory use of protective eye wear at work place.

Improving and maintaining standards and quality of eye protection wear is also important. To reduce the severity of ocular injuries first aid facilities should be readily available at close proximity to the work site to be utilized during an eye injury.

\section{Acknowledgements}

We acknowledge the guidance and support provided by the Dr. SAH Liyanage, Director, National Eye hospital, Colombo Prof. KN Lankathilaka, Senior Lecturer, Department of Community Medicine, and Dr. HMKRNB Senevirathne, Research Assistant, Department of Anatomy, Faculty of Medicine, University of Colombo in conducting this study. 


\section{REFERENCES}

1. Thompson GJ, Mollan SP. Occupational eye injuries: a continuing problem. Occupational Medicine 2009; 59:123-125.

2. Ngondi CE, Chastonay P, Dosso A. Preventing occupational eye trauma (Geneva, Switzerland). J Fr Ophthalmol 2010 Jan; 33:44-9.

3. Chen SY, Fong PC, Lin SF, Chang $\mathrm{CH}$, Chan CC. A case-crossover study on transient risk factors of work-related eye injuries. Occup Environ Med 2009 Aug; 66(8):517-22.

4. Blackburn J, Levitan EB, MacLennan PA, Owsley C, McGwin GJr. A case-crossover study of risk factors for occupational eye injuries. J Occup Environ Med. 2012 Jan; 54:42-7.

5. Hossain MM, Mohiuddin AA, Akhanda AH, Hossain MI, Islam MF, Akonjee AR, Ali M. Mymensingh. Pattern of ocular trauma. Med J .2011 Jul; 20:377-80.

6. Mansouri MR, Hosseini M, Mohebi M, Alipour F, Mehrdad R. Work-related eye injury: the main cause of ocular trauma in Iran.Eur J Ophthalmol 2010 Jul-Aug; 20:770-5.

7. McCall BP, Horwitz IB, Taylor OA. Occupational eye injury and risk reduction: Kentucky workers' compensation claim analysis 19942003.Inj Prev. 2009 Jun; 15:176-82.

\section{CORRESPONDENCE:}

Dr. Madhuwanthi Dissanayake, University of Colombo,

Sri Lanka.

Email-dissamadhu@yahoo.com

Received: July 2017

Accepted: August 2017 